Retno Issroviatiningrum, Denti Wijaya Kusumaningsih, Muh. Abdurrouf Hubungan Kualitas Skenario Dengan Keefektifan Diskusi Kelompok Pada Metode Problem Based Learning Di FIK Unissula

\title{
HUBUNGAN KUALITAS SKENARIO DENGAN KEEFEKTIFAN DISKUSI KELOMPOK PADA METODE PROBLEM BASED LEARNING DI FIK UNISSULA
}

\author{
Retno Issroviatiningrum ${ }^{1}$ \\ Fakultas IImu Keperawatan Universitas Islam Sultan Agung Semarang \\ Corresponding author E-mail : ningrum@unissula.ac.id \\ Denti Wijaya Kusumaningsih ${ }^{2}$ \\ Fakultas IImu Keperawatan Universitas Islam Sultan Agung Semarang \\ Muh. Abdurrouf ${ }^{3}$ \\ Fakultas IImu Keperawatan Universitas Islam Sultan Agung Semarang
}

\begin{abstract}
ABSTRAK
Latar Belakang: PBL merupakan sistem pembelajaran yang dilakukan berkelompok \& kolaboratif, terdapat seorang tutor dan skenario sebagai pencetus diskusi. Faktor penting PBL kualitas skenario, kinerja tutor yang berpengaruh terhadap keefektifan diskusi kelompok \& berdampak pada pencapaian hasil belajar.

Metode: Penelitian ini adalah penelitian dengan menggunakan metode deskriptif korelasi. Teknik pengambilan sampel menggunakan total sampling dengan jumlah responden sebanyak 95 responden.

Hasil: Hasil penelitian diperoleh dari 95 responden, sebagian besar memiliki karakteristik jenis kelamin perempuan dengan persentase $86,3 \%$, kualitas skenario dengan kategori cukup baik $63,2 \%$, \& keefektifan diskusi dengan kategori baik 51,6\%. Pada kualitas skenario dengan keefektifan diskusi $p$-value 0,000 dengan keeratan hubungan kuat $(0,618)$ serta arah hubungan positif.

Kesimpulan dan Saran: Penelitian ini didapatkan ada hubungan kualitas skenario dengan keefektifan diskusi kelompok pada metode belajar PBL di FIK Unissula. Berdasarkan hasil penelitian diharapkan kualitas skenario yang dinilai cukup oleh mahasiswa perlu diperbaiki atau ditingkatkan dan juga mahasiswa ditingkatkan belajarnya agar diskusi berjalan dengan efektif \& dapat mencapai keberhasilan belajar.
\end{abstract}

Kata Kunci : Keefektifan diskusi kelompok, kualitas skenario, PBL

\section{ABSTRACT}

Background: $P B L$ is a learning system that is carried out in groups \& collaboratively, there is a tutor and a scenario as the initiator of the discussion. The important factors of PBL are the quality of the scenario, the performance of the tutor which affects the effectiveness of group discussions and has an impact on the achievement of learning outcomes.

Methods: This study is a research using descriptive correlation method. The sampling technique used total sampling with a total of 95 respondents.

Results: The results of the study were obtained from 95 respondents, most of whom had female gender characteristics with a percentage of $86.3 \%$, the quality of the scenario with a fairly good category of $63.2 \%$, and the effectiveness of the discussion with a good category of $51.6 \%$. On the quality of the scenario with the effectiveness of the discussion $p$-value 0.000 with a strong relationship (0.618) and the direction of the positive relationship.

Conclusions and Suggestions: This study found that there is a relationship between the quality of the scenarios and the effectiveness of group discussions on the PBL learning method at FIK Unissula. Based on the results of the research, it is expected that the quality of the scenarios that are considered adequate by students needs to be improved or improved and also the students' learning is enhanced so that the discussion runs effectively \& can achieve learning success.

Keywords : Effectiveness of group discussions, quality of scenarios, $P B L$ 


\section{PENDAHULUAN}

Keperawatan adalah ilmu terapan, sehingga ilmu yang kompleks harus diterapkan untuk pemecahkan suatu masalah. Masalah keperawatan menggunakan proses berpikir yang lebih luas, yaitu melalui pemikiran kritis. Berfikir kritis sendiri adalah kunci sukses pemecahan suatu masalah. Agar peserta didik dapat menerapkan berfikir kritis dapat melalui strategi pembelajaran yaitu problem based learning disingkat menjadi PBL. Strategi PBL memusat atau memfokuskan pembelajaran pada peserta didik (Lestarini \& Suriana, 2017)

Penggunaan metode pembelajaran PBL oleh perguruan tinggi Indonesia di dasarkan pada Keputusan Mentri Pendidikan No. 323/U/2002 tentang kurikulum perguruan tinggi dan hasil belajar mahasiswa. Metode PBL ini dimulai sejak tahun 2001 oleh beberapa perguruan tinggi di Indonesia (Depdiknas, 2003). Pelaksanaan metode pembelajaran PBL pada semua Program Studi S1 Keperawatan di Indonesia dimulai pada tahun 2008, akan tetapi tidak semua institusi pendidikan keperawatan menerapkan dikarenakan dan pengalaman dan kesamaan pengembangan kurikulum (AIPNI, 2010).

PBL merupakan sistem pembelajaran yang dilakukan secara berkelompok \& kolaboratif. Peserta didik belajar didalam small group discussion atau SGD yang difasilitasi oleh seorang tutor dan sebagai pencetus diskusi peserta didik menggunakan materi pelajaran suatu masalah yang diangkat dari fenomena di lingkungan (Sianipar IMG et al., 2016).

Didalam PBL ada tiga faktor penting, yang pertama masalah/skenario yang di diskusikan, kedua kinerja tutor, dan yang terakhir efektivitas diskusi kelompok (Sianipar IMG et al., 2016). Skenario di dalam metode Problem base learning adalah inti dari keberhasilan kegiatan tutorial PBL, di karenakan skenario adalah pokok kesepakatan dari proses belajar peserta didik. Skenario yang dapat menyediakan semua tujuan pembelajaran, jelas dan singkat sehingga dapat memacu perihal ingin tahu lebih dalam dari peseta didik merupakan skenario yang baik. Untuk mensukseskan diskusi kelompok peserta didik harus berperan aktif dalam berkomunikasi, memiliki minat pada diskusi kelompok dan semua peserta didik terlibat di dalam diskusi. Dengan kualitas skenario yang baik maka diskusi akan berjalan lancar \& efektif (Susanti et al., 2017)

\section{METODE PENELITIAN}

Penelitian ini adalah jenis penelitian deskriptif korelasi, diantaranya jenis penelitian untuk menjelaskan hubungan antar variabel bebas dengan terikat. Pada penelitian ini yang ingin diketahui ialah hubungan antara kualitas skenario dengan keefektifan diskusi kelompok di Fakultas IImu Keperawatan Universitas Islam Sultan Agung Semarang.

Populasi dalam penelitian ini ialah mahasiswa prodi S1 keperawatan semester 7 di Fakultas IImu Keperawatan Universitas Islam Sultan Agung Semarang sebanyak 95 orang. Sampel penelitian disini memakai metode total sampling dimana tehnik pengambilan sampel sama dengan populasi (Sugiyono, 2009). Jadi besar sampel yang dipakai pada penelitian ini sebanyak 95 responden.

Instrumen penelitian menggunakan koesioner demografi, kualitas skenario dan kuesioner keefektifan diskusi kelompok. Koesioner demografi berisi identitas mahasiswa yang meliputi: inisial nama, jenis kelamin, dan kelompok dalam SGD.

Koesioner kualitas skenario terdiri 18 pernyataan skala yang digunakan adalah skala likert Penilaian yang digunakan pada kuesioner yaitu menggunakan kategori respon sebagai berikut : sangat setuju (SS), setuju (S), netral (N), tidak setuju (TS), sangat tidak setuju (STS). Koesioner keefektifan diskusi kelompok terdiri 19 pernyataan skala yang digunakan adalah skala likert Penilaian yang digunakan pada kuesioner yaitu menggunakan kategori respon sebagai berikut : selalu (SL), sering $(\mathrm{SR})$, ragu-ragu (RG), kadang-kadang (KD), 
Retno Issroviatiningrum, Denti Wijaya Kusumaningsih, Muh. Abdurrouf Hubungan Kualitas Skenario Dengan Keefektifan Diskusi Kelompok Pada Metode Problem Based Learning Di FIK Unissula

tidak pernah (TP). Analisis data yang digunakan adalah uji statistic parametric yaitu uji pearson.

\section{HASIL DAN PEMBAHASAN}

1. Analisa Univariat

a. Karakteristik Responden

1) Jenis Kelamin

Tabel 1. Distribusi frekuensi berdasarkan jenis kelamin mahasiswa di Fakultas IImu Keperawatan Semester VII Universitas Islam Sultan Agung Semarang pada bulan Novemer 2020 ( $n=95$ ).

\begin{tabular}{lll}
\hline $\begin{array}{l}\text { Jenis } \\
\text { Kelamin }\end{array}$ & $\begin{array}{l}\text { Frekuensi } \\
(\mathbf{f})\end{array}$ & $\begin{array}{l}\text { Persentase } \\
\%\end{array}$ \\
\hline Laki-laki & 13 & 13,7 \\
Perempuan & 82 & 86,3 \\
\hline Total & $\mathbf{9 5}$ & $\mathbf{1 0 0 , 0}$ \\
\hline
\end{tabular}

Dari tabel 1 bisa diketahui bahwa responden terbanyak ialah berjenis kelamin perempuan yaitu sebanyak 82 responden dengan persentase sebanyak 86,3 \%, sedangkan responden paling sedikit ialah berjenis kelamin laki-laki yaitu sebanyak 13 responden dengan persentase $13,7 \%$.

Hasil penelitian ini didukung hasil oleh peneliti sebelumnya yang berkaitan dengan jenis kelamin menurut Wardani et al., (2018) menyebutkan bahwa pengaruh jenis kelamin terhadap kemampuan berfikir kritis pada peserta didik cukup tinggi, akan tetapi perempuan memiliki kemampuan berfikir kritis lebih baik dibandingkan laki-laki. Dan yang harus lebih diperhatikan dalam meningkatkan kemampuan berfikir kritis yaitu dalam hal menganalisis dan mengevaluasi masalah.

\section{2) Kualitas skenario}

Tabel 2. Distribusi frekuensi berdasarkan kualitas skenario di Fakultas IImu Keperawatan Semester VII Universitas Islam Sultan Agung Semarang pada bulan November $(n=95)$

\begin{tabular}{lll}
\hline $\begin{array}{l}\text { Kualitas } \\
\text { Skenario }\end{array}$ & $\begin{array}{l}\text { Frekuensi } \\
\text { (f) }\end{array}$ & $\begin{array}{l}\text { Persentase } \\
\%\end{array}$ \\
\hline Cukup & 60 & 63,2 \\
Baik & 35 & 36,8 \\
\hline Total & $\mathbf{9 5}$ & $\mathbf{1 0 0 , 0}$ \\
\hline
\end{tabular}

Dari tabel 2 bisa diketahui dari hasil penelitian kualitas skenario tertinggi dengan kategori cukup dengan jumlah 60 responden dengan persentase $(63,2 \%)$, dan terendah dengan kategori baik terdapat 35 responden dengan presentase $(36,8 \%)$.

Hasil penelitian ini juga didukung oleh penelitian Susanti et al., (2017) yang menyatakan bahwa sebagian besar perpendapat sebanyak 91 responden $(54,2 \%)$ menyatakan kualitas skenario baik. Kualitas skenario pada penelitain diatas yaitu baik dan PBL adalah bagian dari proses belajar yang memberikan pemecahan masalah sebagai usaha kolaboratif didalam kelompok SGD. PBL sendiri merupakan strategi proses belajar yang diterapkan pada mahasiswa agar suatu kelompok tersebut kolaborasi dalam memecahkan suatu permasalahan. Peneliti berpendapat bahwa semakin tinggi kualitas skenario semakin baik pula keefektifan diskusi kelompoknya.

3) Keefektifan Diskusi Kelompok Tabel 3 Distribusi frekuensi responden berdasarkan keefektifan diskusi kelompok di Fakultas IImu Keperawatan Semester VII Universitas Islam Sultan Agung Semarang pada bulan Desember $2020(n=95)$

\begin{tabular}{lll}
\hline $\begin{array}{l}\text { Keefektifan } \\
\text { Diskusi } \\
\text { Kelompok }\end{array}$ & $\begin{array}{l}\text { Frekuensi } \\
\text { (f) }\end{array}$ & $\begin{array}{l}\text { Persentase } \\
\%\end{array}$ \\
\hline Cukup & 46 & 48,4 \\
Baik & 49 & 51,6 \\
\hline Total & $\mathbf{9 5}$ & $\mathbf{1 0 0 , 0}$ \\
\hline
\end{tabular}

Dari tabel 3 hasil penelitian diperoleh bahwa responden menyatakan diskusi PBL didalam SGD sebagian besar adalah efektif karena terdapat 49 responden (51,6\%) menyatakan baik. Pada kegiatan PBL mahasiswa harus berpartisipasi aktif sehingga setiap mahasiswa berkontribusi merata dan melengkapi pengetahuan oleh mahasiswa mengenai problem yang sedang dibahas (Wood, 2003).

Hasil penelitian didukung oleh penelitian sebelumnya oleh Susanti et al., (2017) hasil penelitian menunjukkan keefektifan diskusi kelompok sebagian besar 
Retno Issroviatiningrum, Denti Wijaya Kusumaningsih, Muh. Abdurrouf Hubungan Kualitas Skenario Dengan Keefektifan Diskusi Kelompok Pada Metode Problem Based Learning Di FIK Unissula

menyatakan efektif yaitu sebanyak 103 responden $(61,3 \%)$. Peneliti menyimpulkan bahwa keefektifan diskusi kelompok pada metode PBL sudah baik, tidak ada perbedaan antara penelitian ini Peneliti juga berpendapat bahwa semakin tinggi faktorfaktor yang mempengaruhi keefektifan diksusi kelompok yaitu kinerja tutor dan kualitas skenario semakin baik pula keefektifan diskusi kelompoknya.

\section{Analisa Bivariat \\ a. Uji Normalitas}

Tabel 4 Hasil uji normalitas variabel kinerja tutor dan keefektifan diskusi kelompok di Fakultas IImu Keperawatan Universitas Islam Sultan Agung

Semarang pada bulan November 2020 $(n=95)$

\begin{tabular}{|c|c|c|}
\hline Variabel & $n$ & $\begin{array}{c}\text { Sign (2- } \\
\text { tailed) }\end{array}$ \\
\hline & 95 & 0,200 \\
\hline $\begin{array}{l}\text { Keefektifan } \\
\text { Diskusi } \\
\text { Kelompok }\end{array}$ & 95 & 0,077 \\
\hline
\end{tabular}

Dari tabel 4. bisa diketahui bahwa kedua variable penelitian mempunyai nilai $p$ value atau sign (2-tailed) sebesar 0,200 dan $0,077>0,05$ pada uji normalitas yang menggunakan Kolmogorov-Smirnov Test, sehingga dapat disimpulkan bahwa dalam penelitian kedua variable berdistribusi normal. Selanjutnya dilakukan uji statistic parametik menggunakan uji pearson.

\section{b. Uji Pearson}

Tabel 5 Hasil uji pearson hubungan kinerja tutor dengan kefektifan diskusi kelompok di Fakultas IImu Keperawatan

Semester VII Universitas Islam Sultan Agung Semarang pada bulan November $2020(n=95)$

\begin{tabular}{lccc}
\hline Variabel & $\mathbf{N}$ & $\begin{array}{c}\text { Sign } \\
(\mathbf{2}- \\
\text { tailed) }\end{array}$ & $\begin{array}{c}\text { Correla } \\
\text { tion } \\
\text { coeffici } \\
\text { ent }\end{array}$ \\
\hline $\begin{array}{l}\text { Kualitas } \\
\text { Skenario } \\
\text { dengan } \\
\text { Keefektifan }\end{array}$ & 95 & 0,000 & 0,618 \\
\hline
\end{tabular}

diskusi

kelompok

Dari tabel 5 bisa diketahui bahwa nilai sign.(2-tailed) atau p-value pada uji pearson yaitu dengan hasil $0,000<0,05$, sehingga bisa disimpulkan pada penelitian ini ada hubungan antara kualitas skenario dengan keefektifan diskusi kelompok di Fakultas IImu Keperawatan Semester VII Universitas Islam Sultan Agung Semarang. Selain itu diperoleh hasil nilai correlation coefficien yaitu 0,618 menunjukkan bahwa keeratan hubungan antara dua variabel termasuk kategori kuat. Karena correlation menghasilkan nilai positif, maka hubungan yang diperoleh juga positif, artinya semakin tinggi nilai kualitas skenarionya maka semakin tinggi tinggi juga keefektifan diskusi kelompok atau sebaliknya.

\section{KESIMPULAN}

1. Karakteristik responden pada penelitian ini sejumlah 95 responden. Responden berjenis kelamin perempuan sebanyak 82 orang dengan persentase $(86,3 \%)$.

2. Kualitas skenario di FIK Universitas Islam Sultan Agung dengan kategori cukup sebanyak 60 responden $(63,2 \%)$.

3. Keefektifan diskusi kelompok di FIK Universitas Islam Sultan Agung dengan kategori baik terdapat 49 responden $(51,6 \%)$.

4. Terdapat hubungan yang dignifikan antara kualitas skenario dengan keefektifan diskusi kelompok pada metode PBL di Fakultas IImu Keperawatan Universitas Islam Sultan Agung Semarang, dengan nilai sign.(2tailed) atau p-value sebesar 0,000 $<0,05$ dan keeratan hubungan yaitu kuat dengan nilai coefficient correlation sebesar positif 0,618.

\section{DAFTAR PUSTAKA}

AIPNI. (2015). Sistem Pendidikan Tinggi Keperawatan di Indonesia.

Depdiknas. (2003). Undang-Undang Sistem Pendidikan Nasional. Departemen Pendidikan Nasional. 
Lestarini, A., \& Suriana, S. N. (2017). Optimalisasi Peran Fasilitator untuk Meningkatkan Keefektifan Diskusi Kelompok pada Blok Musculoskeletal System and Disorders Subjek yang dilibatkan dalam proses pembelajaran blok Musculoskeletal System and Disorder adalah mahasiswa semester Effectiveness. Warmadewa Medical Journal, 2(2), 52-59. https://doi.org/10.22225/wmj.1.2.394.7 1

Sianipar IMG, Hilmanto D, Siregar IMP, Husin F, Sutedja E, \& Sukandar H. (2016). Hubungan Kinerja Tutor dan Kualitas Kasus Skenario Terhadap Keefektifan Kelompok pada Metode Belajar Problem Based Learning. ljemc, 3(2), 1-7.

Sugiyono. (2009). Metode Penelitian Kuantitatif, Kualitatif, dan R\&D (Dr. Ir. Sutopo. S.Pd. MT (ed.)). ALFABETA, cv.

Susanti, P. F. E., Lisiswanti, R., Soleha, T. U., Saputra, O., \& Okyafany. (2017). Hubungan Kualitas Skenario Terhadap Keefektifan Diskusi Problem- Based Learning ( PBL ) Blok Emergency Pada Mahasiswa Fakultas Kedokteran Universitas Lampung The Relationship of Quality Scenario To Effectiveness Of The Problem- Based Learning ( PBL ) Disc. Medulla, 7(4), 157-163. http://juke.kedokteran.unila.ac.id/index .php/medula/article/view/1768

Wardani, W., Astina, I. K., \& Susilo, S. (2018). Pengaruh Gender terhadap Kemampuan Berpikir Kritis Siswa SMA Program IPS pada Mata Pelajaran Geografi. Jurnal Pendidikan, 3(12), 1530-1534.

http://journal.um.ac.id/index.php/jptpp/

Wood, D. F. (2003). Problem based learning what is problem based leaening ? $\mathrm{Bmj}$, 10-39. 